\title{
Developing and Leveraging Business Intelligence Systems for Decision Making in Organizations
}

\author{
Monirah Almalki \\ Department of Information Systems \\ Faculty of Computing and Information Technology \\ King Abdulaziz University, Jeddah, Saudi Arabia
}

\begin{abstract}
In recent years, Business Intelligence (BI) has started to play a significant role for businesses regarding of development and helping to increase achievements and supporting decisions making. Factors such as changing, innovation, globalization, and sustainability in changing markets environment accelerate the shift towards using BI. One of the difficulties that are affecting the business world is the increasing volume of data that is everywhere. BI allows for a large amount of data from different sources to be converted into helpful information, knowledge, and insights. This paper explains that the BI systems are not just about tools. Nevertheless, it is a wide range of applications and processes not for getting data out of the warehouse, but also for getting data into a warehouse, and for visualizing the trend in the data. This paper aims to investigate the concepts of BI, its framework, the relationship between BI and DSS, benefits of BI, its applications, its software and tools, and finally issues of implementation BI.
\end{abstract}

\section{General Terms}

Business Intelligence (BI), Decision Making, Decision Support Systems (DSS), Organizations, Dashboard

\section{Keywords}

Business Intelligence (BI), Decision Making, Decision Support Systems (DSS)

\section{INTRODUCTION}

The business climate around the world is constantly changing and becoming more complex every day. Issues like changes in customer demand, updated government regulation, increased competition, technological innovations and environmental factors compose today's business environment. Organizations in public and private should respond quickly to these changing conditions if they want to survive. They have to be more agile, more innovative; they have to make complex decisions, frequently, and quickly. To make those decisions, managers need to have on-demand access to business intelligence tools and applications. Managers must start asking, are we on the right track? Did we make the right decision? How can we respond to competition and make a prediction? The organization lives and dies by how well it can answer these types of questions; this is where computerized support for decision-making comes into play [2].

It is often challenging to control the large volume of information, which is essential for the business to keep up to date and to support decision-making [1]. On the other hand, there is an increasing need for BI in organizations to produce faster decisions and to develop new products or to change plans. Accordingly, this paper tries to focus on these needs and shows the possible solutions to these needs by using BI techniques. In this paper, we are going to discuss the conceptual foundations of BI and how managers are increasingly dependent on decision support systems, business intelligence tools, and applications to make decisions.

This paper aims to display the concepts, benefits, framework, tools for BI and explain how to transform data into knowledge to take better decisions by using certain technologies and tools of BI. The paper is organized as follows. Section 2 displays information about BI concepts, benefits, and its applications. Next, Section 3 presents frameworks of BI and its components. Section 4 displays visuals analytics and BI. Then, section 5 provides challenges and issues regarding implementation of BI. After that, Section 6 presents BI software and tools. In Section 7, we show the relationship between DSS and BI. The last section is the conclusion of the research.

\section{BUSINESS INTELLIGENCE}

BI systems are the newest in a long series of systems that have been developed through the previous years to support organizations activities and decision-making. Figure 1 represents the growth of the systems that were created to support the decisions. For instance, the development of reports from static reports to interactive reports and dashboards. As shown in Figure 1, the improvements started by using MIS. MIS did not help managers in decision making; the output was in the form of non-interactive periodical reports that present data. Consequently, DSS and Group DSS were designed to support unstructured and semi-structured decisions in a more cooperating way. Throughout the 1970s, DSS create search function in records and documents; this led to creating document-based systems with the evolution of relational databases management system. The possibility of obtaining an amount of data and improved modeling ability led to creating executive information systems (EIS). These systems used the predefined information to facilitate managerial inquiry. With EIS started to use data warehouse and OLAP, the concept of knowledge management systems (KMS) arose as a result of various impacts on the support of organizational knowledge. As shown in Fig 1, the newest one in the track of information systems progression is BI.

$\mathrm{BI}$ is designed to help in the process of data analysis and support decision-making. BI supported by the combination of databases from a different business area to deliver new insights that may guide to give better decision making. As a result of improvement in information systems that support decision making; the progression was developed from standard and regular annual reports that did not let for online inquiries to interactive reports, dashboards and available on demand to managers. 


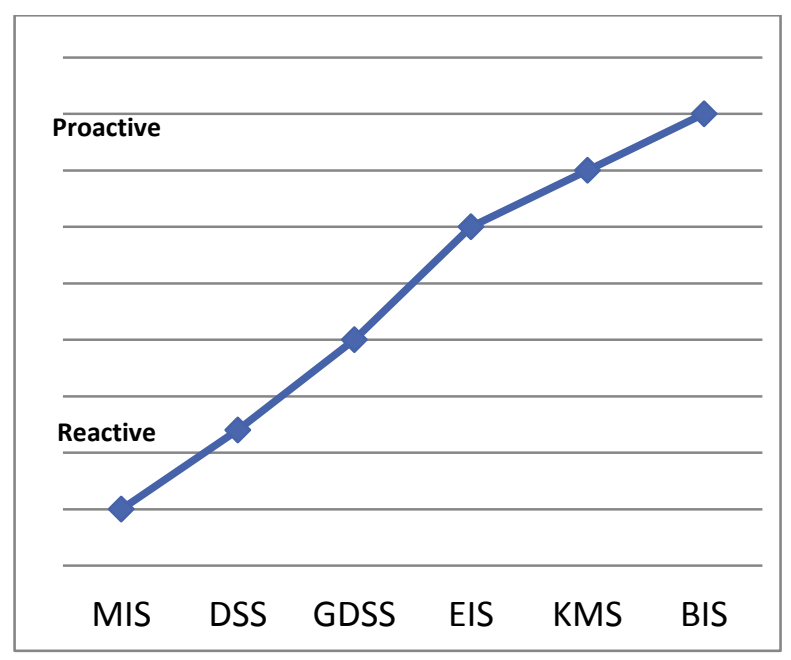

Fig 1: The growth of systems that support decisionmaking process [2]

\subsection{BI Concept}

$\mathrm{BI}$ is a set of process to analyze data and present accurate information to help leaders and other workers to make more informed decisions [2]. BI comprises of different tools, methodologies, and applications that allow business to gather data from internal and external sources. Then, BI prepare it for analysis, create dashboards, reports, and data visualizations to make the analytical results available to decision makers and operational workers. According to Galliers et al., BI is a broad category of tools for gathering, saving, analyzing, and giving access to information to support organizations make better decisions [3]. BI is an umbrella term that includes data warehousing, analytical tools, and applications. The BI process is based on the transformation of the data to information, then to decisions, and finally to action [4].

BI takes data from various sources, transforms these data into information through people, processes, and analytical tools to make better decisions which will improve the performance of the business or an organization. Moreover, Business Intelligence (BI) is a technique of using advanced tools to collect and examine information about the business in order to better understand the opportunities, strengths, weaknesses, and to monitor the organization's competitors [3].

\subsection{BI Benefits}

BI applications help organizations make significant, datadriven decisions by interpreting and transforming large amounts of structured and unstructured data. According to Huie, one of the important benefits of BI is its ability to transform data of the business from different sources into important statistics for decision making which is essential for executive's managers [5]. Moreover, BI helps organizations to decide what's working for the business and why. The benefits of BI applications include enhancing decision-making process; improving operational performance; making new incomes; obtaining competitive advantages; BI reduces IT infrastructure expenses by reducing unnecessary data extraction processes; provides time savings for users and data suppliers; gives better information and decisions; support for the accomplishment of strategic business objectives [6].

According to [4], BI provides benefits to organization in term of decision making, management, costs, service quality, and marketing as follows: BI provide faster and more accurate business reporting, improved decision-making process, improved customer satisfaction, reduction in costs, increase in revenue, improved quality of information and communication, and increase in market share.

\subsection{BI Applications}

Recently, BI has been implemented in many fields to give input to the decision-making for example, E-learning, financial, higher education, strategy making, and other areas. BI can integrate the data from all levels to give the right information at the right time [7]. According to Sharda [2], BI applications can be divided into three kinds of applications: strategic, tactical and operational applications.

Strategic BI applications support directors, managers, and financial analysts to evaluate growth in accomplishing enterprise and long-term goals such as improving productivity, increasing market share and income, better customer retention, and reducing costs. For example, strategic dashboards can show enterprise-wide strategic objectives and equivalent KPIs [8]. Strategic decisions executed by top executive managers to create long-term planning. It focuses mostly on demographic, and industry trends and addresses broad issues to accomplish general goals [9].

Tactical BI Applications focus on evaluating short-term goals within specific business domains, such as sales, customer service, and marketing. For example, Tactical BI measures the business's growth depending on related trends by using the tactical or analytical dashboards [2]. Tactical BI Applications can measure progress versus a particular preset goal, such as a certain target or budget [9].

Operational BI applications provide solutions for observing and enhancing business processes, such as loan processing, inventory management, and call center operations. Operational BI applications are developed to support employees to achieve their regular business transactions. Order processing and shipping by using operational dashboards are usually used at the operational level, where operations take place. Users can track updates daily, weekly, or monthly by using real-time graphs and reports with analytical functionality to conduct a root cause analysis [10].

\section{BI FRAMEWORKS AND ITS COMPONENTS}

In this section, we will cover the components of a BI framework. The first component of a BI framework is data sources which can be in terms of relational, multidimensional, or columnar databases. Data comes from different sources such as Customer Relationship Management (CRM), Supply Chain Management (SCM) and Enterprise Resource Planning (ERP). After data is collected from various sources, it is managed by extraction, transformation, and loading data (ETL process, the second component of BI framework). Then, it is stored inside data warehouse (the third component of BI framework) to correct multidimensional form. Data Warehouse serves as the data source for BI interface (the fourth component of BI Framework) [2]. BI framework contains a user interface for interacting with an organization's data in different styles. There are five styles of BI: data mining; OLAP analysis; data visualization; dashboards and enterprise reporting. BI styles enable users to quickly adapt to new business requirements and evolving source of information in order to do their jobs more efficiently. The 
number and the range of users depend on the style of BI, and they are not all the same. We will explore different styles of the user interface in BI framework as follows:

Data Source

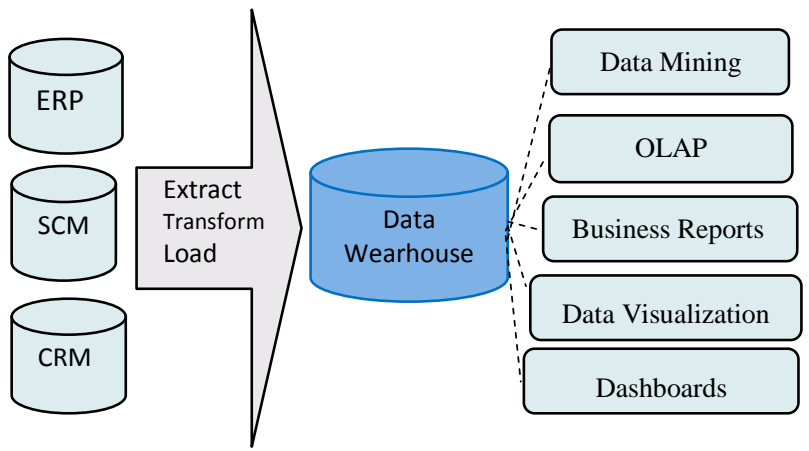

Fig 2: Framework of BI [7]

\subsection{Data Mining}

Data mining techniques use predictive analytics statistical to predict future events. For example, whether a consumer is expected to switch to new competitors, what the client is possible to buy next, and whether this customer is credit worthy. Predictive analytics leverages three distinctive types of algorithms to do its analysis. The first type, clustering algorithms that are used to segment customers into different groups to target specific promotions to them. Second, classification algorithms are used to analyze the historical behavior of groups of customers or events with similar characteristics to predict future behaviors in similar groups. Finally, association's algorithms that can help to establish the relationships among the items that occur together [2], [11].

\subsection{OLAP}

OLAP applications can help organizations to determine where they are and where they should be going and how to target the right customers at the right time for a product or service. OLAP is useful for budgeting, financial reporting, employee performance tracking, and manufacturing applications. OLAP comes in four types or styles, the relational OLAP or ROLAP, multidimensional OLAP, otherwise known as MOLAP, HOLAP for Hybrid Online Analytical Processing, and desktop OLAP. OLAP and ROLAP both allow analysis of data by using relational or multidimensional data model, but there are a few key differences [2], [7].

ROLAP tools can access data in the relational database using queries to access information upon user request; this is the most common type of OLAP. On the other hand, MOLAP uses a multidimensional cube; to do so, the data should be preprocessed first, then provided in the cube; as a result, the decisions will be analyzed faster because of the ability to pivot, slice, and dice. HOLAP provide a storing part of the data in MOLAP store and the rest part of the data in ROLAP store [2], [12], [13].

\subsection{Business Reports}

Business reports are either produced to inform internal audiences like stakeholders and decision makers or external government audiences. The initial business reports change depending on the audience. Different kinds of reports serve various business activities such as to ensure proper functioning, provide results of analysis, persuade others to act, and creating the organizational memory. Data of reports is formatted into text, tables, graphs, and charts. Reporting application helps the user first select the data to be displayed, and then filter the data according to specific criteria like only sold in my store or sold in the last six months [2].

There are different types of business reports depending on the type of the question that asks. The standard reports answer for basic questions such as what happened and when did it happen like quarterly financial reports. More targeted questions such as how often does this happen require a custom ad hoc report. If that question requires a deeper investigation, such as sorting and exploring more information, query drill down or OLAP reports will allow the user to manipulate all the variables. The answer to those types of questions can be represented via dashboards, balanced scorecards, or metrics management reports, depending on what the user is trying to present [14]. Reports are either published based on a preset schedule of events or on-demand basis. These will depend on the alerts and transaction services capabilities embedded in the BI platform [2], [13].

\subsection{Data Visualization}

Data visualization provides a self-service approach for data discovery. So, Individuals and companies no longer have to rely on IT departments; as a result, collecting, organizing, manipulating, and visualizing data is becoming common practice. In the data visualization process, the user identifies a set of data from databases, data warehouses, or from spreadsheets. Then the user can familiarize with the data and begin to understand any relationships that he sees. Next, he applies visualizations to that data to help him to screen patterns, problems, and trends. Finally, the user utilizes his analysis by filtering the data, creating new calculations, and adding new views to the data [10].

Many types of data can be visualized. Essentially, there are three categories of data. First, the data that contain simple attributes like the colors in a crayon box or items on the shelf at a larger store. These data can be counted, but not ordered or aggregated. Next, the data that contains ordinal attributes which can be counted and ordered, but not aggregated such as dates on a date line or grades of students in an English class. These types of data have a relationship in the sequence. The third type of data is quantitative metrics data that can be counted, ordered, and aggregated. These data points can include revenue, costs, profits, and the number of customers, temperature, or time [10].

\subsection{Dashboards}

A dashboard consists of a variety of charts, performance bars, spot lines, gauges, meters, stoplights, and geographic maps. They require minimal training to use. Dashboards combine timely data from a variety of systems into a single interface. Multiple visualizations get consolidated into dashboards which can be integrated into one multi-layer dashboard. It allows users to both get at a glance view or down to get an indepth view of performance [15].

The dashboard can go from broad views about the entire organization to a specific focus on a product or process [4]. It can contain either long-term strategic views of performance, shorter-term views on operations business and tactical progress on specific initiatives. For examples, dashboards that are built for a store; managers can show a store operation information, key performance indicators, and organization benchmark. The user needs to have a clear understanding of what he is trying to achieve. Regardless of how good the 
visualizations are, if the information is a poor standard, then the dashboard will never be as efficient as it could be [15], [16].

From the analysis, we can summarize the process of BI into five main steps to convert data from the first step "data source" to final step "information delivery" as shown in the following table and figure 3 .

\section{Table 1. The Process of BI}

\begin{tabular}{|c|l|}
\hline $\begin{array}{c}\text { Source } \\
\text { Systems }\end{array}$ & $\begin{array}{l}\text { BI deals with different data sources by bringing the } \\
\text { raw data to data warehouses. These source systems } \\
\text { can be on different platforms and store data in many } \\
\text { different formats. }\end{array}$ \\
\hline $\begin{array}{c}\text { Integration } \\
\text { Service }\end{array}$ & $\begin{array}{l}\text { BI manipulate data by extracting, transforming, and } \\
\text { loading services. }\end{array}$ \\
\hline $\begin{array}{c}\text { Data } \\
\text { Management } \\
\text { Service }\end{array}$ & $\begin{array}{l}\text { Data management services employ a variety of } \\
\text { architectures, technologies, and data models } \\
\text { including data marts, data warehouses, and OLAP } \\
\text { cube data. }\end{array}$ \\
\hline $\begin{array}{c}\text { Reporting } \\
\text { and } \\
\text { Analytical }\end{array}$ & $\begin{array}{l}\text { A collection of tools is available for manipulating and } \\
\text { analyzing the data for reporting via business } \\
\text { performance management dashboards and scorecards. }\end{array}$ \\
\hline $\begin{array}{c}\text { Information } \\
\text { Delivery }\end{array}$ & $\begin{array}{l}\text { Different information delivery tools and applications } \\
\text { can communicate the BI to many different users } \\
\text { including IT developers, analysts, information } \\
\text { workers, managers, executives, front line workers, } \\
\text { suppliers, and customers. }\end{array}$ \\
\hline
\end{tabular}

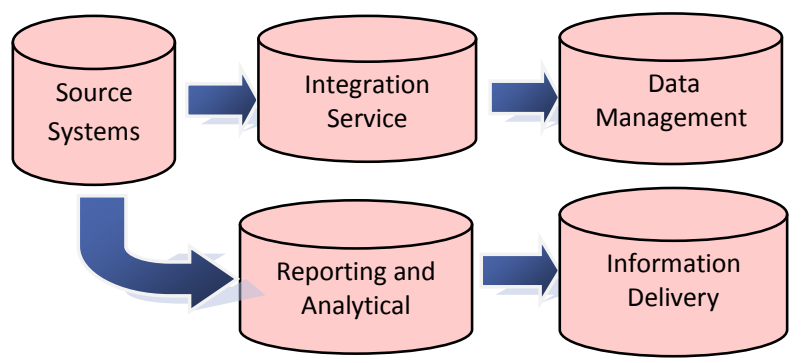

Fig 3: Steps of BI Process [2]

\section{VISUALS ANALYTICS AND BI}

Technologies are continually merging with one another. Advancements and breakthroughs are not always about new technologies. They are often about integrating existing technologies and delivering them together. Visual analytics combines information visualization with predictive analysis. Information visualization is closely related to regular reports, scorecards, and dashboards. It helps answer the question, what is happening or what happened? That is the focus of the descriptive analytics. Predictive analytics is associated with forecasting, segmentation, correlation analysis, and seeks to answer the question, why is it happening? Putting information visualization and predictive analytics together will provide visual analytics [15].

The word analytics has replaced the previous components of decision support systems technologies; it represents a set of techniques, computer technology, management science and statistics to solve business difficulties. Using analytics can either be descriptive, predictive, or prescriptive. Descriptive analytics states to know what is happening within the company or organization. The answer will come from the standard reports and ad hoc reports. Predictive analytics tries to figure out what is likely to occur in the future such as forecasting statistical analysis and predictive analytics. Several techniques fall under the predictive analytics umbrella. For example, Amazon uses market baskets to suggest related products that may interest a consumer. Through forecasting statistical review and alerts, predictive analytics provides a window into possible future. However, to figure out the best course of action to get the best possible future, organizations must employ prescriptive analytics such as optimization techniques. Organizations have used prescriptive analytics to set prices, create production plans, and identify the best locations for facilities such as bank branches. The objective here is to deliver a recommendation or decision for a particular action [2], [17], [18].

\section{CHALLENGES AND ISSUES OF IMPLEMENTATION BI}

BI focuses on managing data to support decision-making process for the executives and directors. According to [11] who conducted a study about BI implementation in the organizations, organizations still face some challenges to implement BI. According to the literature; there are some limitations in the BI application. In this section, We will discuss some of these constraints as follow: issues related to retrieving data on reports such as wasting an amount of time on retrieving data due to several definitions on the same object;different data format, multiple data sources and different software used lead to various data that representing the same thing. As a result, this also may give rise to a lack of trust in the reports and analysis presented to the users [16]. Moreover, data is not clear and accessible for all users; this may lead to the decrease in transparency and reliability of the data. On the other hand, when the data is growing continuously, the filtering and analysis processes of the necessary data become challenging and critical.

Issues related to strategic goals, BI would not add value to the core business processes if it did not align with the organization's strategic goals. Issues related to users, the end user is not aware of the available resources and how the BI environment can be used because overview may still be missing even after BI created and executed. Another issue is related to the cost required in implementing BI. BI database, tools, and systems need many expenses to be invested [14]. According to [4], they have divided BI challenges into three categories based on the usage and the solution. The challenge of usage like the processes of building reports are sometimes too complex, the handling is too difficult or users using the BI solution are not adequate. So, the training is very necessary for users to gain a better understanding of how BI work. The second challenge, which depending on the solution covers difficulties that are connected to the solution and data quality of the BI solution such as poor security function, software errors, inconsistent data, inadequate support, and low speed of the product. The third $\mathrm{BI}$ challenge is the challenge related to the interface such as problematic conflation of data and limited data export function [17], [19].

\section{BI SOFTWARE / TOOLS}

In this section, We will provide an analysis comparison of the most common software for BI that the organizations used. In this comparison, We list the criteria that the organizations should take into consideration to exactly choose the correct software. The choice process of BI software/ tools depends on many aspects like the functionality, financial resources, and human resource. 
From the four software we analyzed in Table 2, we notice that all BI software/ tools are growing in quality, features, and capabilities. We cannot say which is best, but it depends on requirements that the organization needs. These software are Power BI Desktop, Pentaho, Tableau, and JasperSoft [21], [22], [23], [24].

Table 2. Comparison of Software of BI

\begin{tabular}{|c|c|c|c|c|}
\hline & Power BI Desktop & Pentaho & Tableau Desktop & JasperSoft \\
\hline Founded & 2013 & 2004 & 2003 & Founded in 2001 \\
\hline Category & $\begin{array}{l}\text { Cloud business intelligence } \\
\text { software }\end{array}$ & $\begin{array}{l}\text { open-source } \\
\text { platform }\end{array}$ & $\begin{array}{ll}\text { Cloud } & \text { business } \\
\text { intelligence } & \end{array}$ & Open Source \\
\hline $\begin{array}{l}\text { Download and } \\
\text { Installation }\end{array}$ & Available for Windows only. & $\begin{array}{lll}\text { Available } & & \text { for } \\
\text { Windows, Mac } & \text { OS, } \\
\text { and Linux } & & \end{array}$ & $\begin{array}{llc}\text { Available } & & \text { for } \\
\text { Windows, Mac } & \text { OS, } \\
\text { and Linux } & & \end{array}$ & $\begin{array}{l}\text { Available for Windows, } \\
\text { Mac OS, and Linux }\end{array}$ \\
\hline User Interface & $\begin{array}{l}\text { The user interface will look } \\
\text { familiar to users who are } \\
\text { already familiar with } \\
\text { Microsoft Products. It is easy } \\
\text { to use, and features are laid out } \\
\text { intuitively. }\end{array}$ & $\begin{array}{l}\text { The user interface } \\
\text { gives an easy to use } \\
\text { and interactive web- } \\
\text { based interface. }\end{array}$ & $\begin{array}{l}\text { The user interface is } \\
\text { intuitive and easy to } \\
\text { learn. They mark menu } \\
\text { next to the data pane is } \\
\text { the key to master. }\end{array}$ & $\begin{array}{l}\text { The user interface } \\
\text { customization may } \\
\text { require knowledge of } \\
\text { Java. Also, the client GUI } \\
\text { tools are not as friendly as } \\
\text { they could be. }\end{array}$ \\
\hline $\begin{array}{l}\text { Dashboard } \\
\text { /Reports }\end{array}$ & $\begin{array}{l}\text { There are several techniques to } \\
\text { build a dashboard - from } \\
\text { scratch, from a report, from a } \\
\text { dataset, from the database and } \\
\text { by duplicating an existing } \\
\text { dashboard. It combines on- } \\
\text { premises or cloud-born data. }\end{array}$ & $\begin{array}{l}\text { Provide analysis, } \\
\text { dashboard and data } \\
\text { mining capabilities }\end{array}$ & $\begin{array}{l}\text { Provide } \\
\text { Report/Dashboard } \\
\text { building is a breeze - } \\
\text { Beautiful reports with } \\
\text { great design embedded, } \\
\text { dashboards with filters } \\
\text { easily set up }\end{array}$ & $\begin{array}{l}\text { Give advanced report } \\
\text { writing features. }\end{array}$ \\
\hline Cost & $\begin{array}{l}\text { Free for organizations that } \\
\text { have office365. Users can } \\
\text { publish their reports to the } \\
\text { power BI free. Power Pro can } \\
\text { be purchased for } 9.99 \$ \text { per } \\
\text { user. }\end{array}$ & $\begin{array}{l}\text { The pricing is available } \\
\text { by quote only. }\end{array}$ & $\begin{array}{l}\text { Tableau Desktop: } \\
\text { 2000USD/user } \\
\text { (perpetual license) }\end{array}$ & $\begin{array}{l}\text { Professional: } \\
\text { 4 Core Single Instance \& } \\
\text { Unlimited Users - } \\
\text { Premium Support } \\
\text { 37500USD/year, Standard } \\
\text { Support 29000USD/year }\end{array}$ \\
\hline $\begin{array}{l}\text { Data } \\
\text { Manipulation }\end{array}$ & $\begin{array}{l}\text { Power BI's powerful data } \\
\text { modeling features allow users } \\
\text { to add custom data fields and } \\
\text { modify the default properties } \\
\text { of each data field in the data } \\
\text { modeling tab in the tool }\end{array}$ & $\begin{array}{l}\text { Pentaho } \\
\text { Integration is ata } \\
\text { comprehensive ETL } \\
\text { platform letting to } \\
\text { prepare, access, } \\
\text { analyze and acquire } \\
\text { value from both } \\
\text { traditional and big data } \\
\text { sources }\end{array}$ & $\begin{array}{l}\text { Tableau allows users to } \\
\text { create calculated fields } \\
\text { and modify default } \\
\text { properties of each data } \\
\text { field }\end{array}$ & $\begin{array}{l}\text { Jaspersoft's provide data } \\
\text { analytics used to model } \\
\text { manipulate and visualize } \\
\text { data using OLAP to } \\
\text { identify problems and } \\
\text { make better decisions } \\
\text { immediately. }\end{array}$ \\
\hline Capabilities & $\begin{array}{l}\text { Focus more on non-technical } \\
\text { business users by providing } \\
\text { self-service BI solutions. }\end{array}$ & $\begin{array}{l}\text { Pentaho's focus is on } \\
\text { data integration, ETL, } \\
\text { and workflow } \\
\text { automation. }\end{array}$ & $\begin{array}{l}\text { Tableau focuses more } \\
\text { on explore trusted data } \\
\text { in a secure and scalable } \\
\text { environment. }\end{array}$ & $\begin{array}{l}\text { The Jaspersoft focus is } \\
\text { more on reporting and } \\
\text { analysis. }\end{array}$ \\
\hline
\end{tabular}

\section{DECISION MAKING, BI AND DSS}

Decision-making is embedded into almost all tasks of business including planning, organizing, commanding, controlling, and coordinating. Therefore, decision-making is one of the most significant responsibilities of managers. The steps managers take to make decisions remain still consistent. These usually include defining the problem, constructing a model, identifying and evaluating possible solutions, and finally, recommending a potential solution. Managers face structured decisions like choosing whether to make or buy a new product or service, how to find an appropriate inventory level, or how to choose an opportunity investment strategy [2]. They also confront semi-structured decisions like trading bonds or setting marketing budget for new products. These decisions rely on both standard solution procedures and 
human judgment. BI can help with both unstructured and semi-structured decisions. The process of store and access vast amount of information well beyond the limited ability of the human mind. The organizations usually need to use different software programs, such as Access, Excel, and many database applications to keep track of the large quantity of data in business, which is an inefficient process. BI systems allow organizations to collect, store, access and analyze data to support decision-making. These systems represent BI in the areas of customer support, customer profiling, product profitability, market research, market segmentation, inventory and statistical analysis. BI applications have moved from processing transaction to analyzing problems and recommending possible solutions. Managers now have information at their fingertips to be accessed anytime, anywhere, and from any device. We conclude from the previous studies that the BI systems are unlike the past forms of DSS at some points (shown in Table 3 which provides a detailed analysis of the differences between DSS and BI). Table 3 shows that BI is a wider term that includes the concept of a DSS [6], [8], [20]:

Table 3. Differences between DSS and BI

\begin{tabular}{|c|c|c|}
\hline & DSS & $\mathrm{BI}$ \\
\hline Functionalities & $\begin{array}{l}\text { DSSs are used to support exact decision } \\
\text { making. }\end{array}$ & $\begin{array}{l}\text { BI systems are geared to provide precise information to } \\
\text { support unstructured decisions and make new knowledge by } \\
\text { using data mining. }\end{array}$ \\
\hline Types of data & $\begin{array}{l}\text { DSS can use any source of data including a } \\
\text { data warehouse. }\end{array}$ & $\begin{array}{l}\text { BI uses integrated data from data warehouses with different } \\
\text { data sources and formats. }\end{array}$ \\
\hline Types of users & $\begin{array}{l}\text { DSS are usually oriented toward end users, } \\
\text { analysts, and middle-level managers. DSS } \\
\text { supports decision-making directly. }\end{array}$ & $\begin{array}{l}\text { BI orients itself toward executive's managers and strategic } \\
\text { decision-making. }\end{array}$ \\
\hline Types of tools & $\begin{array}{l}\text { DSS tends to use custom tools to focus on } \\
\text { structured and unstructured decisions. }\end{array}$ & $\begin{array}{l}\text { BI tends to be developed with commercial tools that gather } \\
\text { and control unstructured and structured data that are } \\
\text { increasing in real-time in data warehouses. }\end{array}$ \\
\hline Uses & $\begin{array}{l}\text { DSS largely oriented in academia. DSS was } \\
\text { used in theories and cognitive science. }\end{array}$ & $\begin{array}{l}\text { BI came from the software industry to support business } \\
\text { sectors. }\end{array}$ \\
\hline Scale of use & $\begin{array}{l}\text { Administrators use DSS on a small scale, at an } \\
\text { individual preference to a decision making. }\end{array}$ & $\begin{array}{l}\text { BI systems tend to be much larger in scale, support many } \\
\text { users, and use different technologies to deliver information, } \\
\text { which may include OLAP data structures. }\end{array}$ \\
\hline Amount of data & $\begin{array}{l}\text { DSS did not deal with a large amount of data } \\
\text { such as big data. }\end{array}$ & $\begin{array}{l}\text { BI applications deal with the large volume of data 'Big Data' } \\
\text { and 'data mining' which have given new possibilities for } \\
\text { discovering knowledge. }\end{array}$ \\
\hline Interface & $\begin{array}{l}\text { DSS has an interface where the users can make } \\
\text { scenarios, get reports, and create the } \\
\text { visualization to take the right decision. }\end{array}$ & $\begin{array}{l}\text { BI interface has many functions such as data mining, OLAP } \\
\text { tools, data visualization, dashboards, and reporting where the } \\
\text { users can transfer a large amount of raw data to meaningful } \\
\text { information. }\end{array}$ \\
\hline
\end{tabular}

\section{CONCLUSION}

We conclude that BI has many benefits and capabilities for business. Organizations in a different size, business type or positioning can benefit from the BI implementation in support decisions, strategies, and management. The main goal of this paper was to explore the BI area by presenting a variety of elements involved in theories and practice within organizations. In addition, we have presented BI concept, BI frameworks, components, benefits, applications, and limitations of implementation of BI. Moreover, we have focused on the differences between BI and DSS. As a final concluding, BI became important in various fields; in overall, organizations need to consider different factors when implementing BI, such as BI empowerment, integration, and flexibility.

\section{REFERENCES}

[1] A. P. G. B. R. C. a. X. T. R. Harrison, "The role of technology in the management and exploitation of internal business intelligence," Journal of Systems and Information Technology," vol. 17, no. 3, 2017.

[2] R. Sharda, D. Delen and E. Turban, Business Intelligence and Analytics: Systems for Decision Support, 10th Edition ed., New York: Pearson Education, 2015.

[3] A. S. a. R. Galliers, "Towards an understanding of the role of business intelligence systems in organizational knowing," Info Systems J, vol. 26, no. 339, 2016.

[4] S. M. N. A. R. A. A. H. H. N. S. Ahmad Fadhil Yusof, "Implementation Issues Affecting the Business Intelligence Adoption in Public University," ARPN Journal of Engineering and Applied Sciences, vol. 10, no. $23,2015$. 
[5] C. Huie, "Perceptions of Business Intelligence Professionals about Factors Related to Business Intelligence Input in Decision Making," 2014.

[6] J. Bernardino, "Open Business Intelligence for Better Decision-Making," International Journal of Information Communication Technologies and Human Development, vol. 5, no. 2, pp. 20-36, 2013.

[7] M. T. a. P. V. M. Aruldoss, "A Survey on Recent research in business intelligence," Journal of Enterprise Information Management, vol. 38, no. 4, 2014.

[8] C. R. V. M. Ana Madureira, Computational Intelligence, and Decision Making: Trends and Applications, Springer Science \& Business Medi, 2012.

[9] D. STODDER, "Applying Self-Service Business Intelligence Technologies to Data-Driven Objectives," TDWI, 2015.

[10] E. S. S. Ö. Dag Näslund, "Business Intelligence a Maturity Model Covering Common Challenges," Faculty of Engineering at Lund University, 2014.

[11] Z. A. J. Y. a. A. D. N. Hani, "An Integrated Framework of Business Intelligence and Analytic with Performance Management System: A Conceptual Framework," Science and Information Conference, 2015.

[12] M. N. a. I. Z. M. Miškuf, "Application of Business Intelligence Solutions from Microsoft and IBM on Manufacturing Data," IEEE, 2016.

[13] S. Atre, "How's Business? Ask Your Dashboard," 2012. [Online]. Available: http://www.technologytransfer.eu/article/100/2012/4/Ho w\%E2\%80\%99s_Business_Ask_Your_Dashboard.html.

[14] C. White, "Critical Agility: Operational BI Generates Faster and Smarter Decisions.," Teradata Magazine, vol.
9, no. 1, 2015. "A Guide to Creating Dashboards People Love to Use," 2015 Juice, Inc., US, 2015.

[15] "How to Create Compelling Business Dashboards," England.

[16] L. K. a. J.-P. K. Noushin Ashrafi, "The Impact of Business Intelligence on Healthcare Delivery in the USA," Interdisciplinary Journal of Information, Knowledge, and Management, 2014.

[17] V. Pham, "Best Practices in Data Visualizations," MicroStrategy, 1 Jun 2014. [Online]. Available: https://www.microstrategy.com/Strategy/media/downloa ds/training-events/microstrategy-world/2014barcelona/MSTRWorldEU2014_T1_S3_Best_Practices_ i n_Data_Visualizations.pdf?ext=.pdf. [Accessed 8 May 2017].

[18] B. W. a. M. L. Ossimitz, "The Impact of Business Intelligence on the quality of decision making - a mediation model," 2015.

[19] T. Poleto, "The Roles of Big Data in the DecisionSupport Process: An Empirical Investigation," Springer International Publishing, 2015.

[20] "Create stunning reports and visualizations with Power BI Desktop," Power BI Desktop, 2017. [Online]. Available: https://powerbi.microsoft.com/en-us/desktop/.

[21] "A Comprehensive Data Integration and Business Analytics Platform," Pentaho, 2017. [Online]. Available: http://www.pentaho.com/.

[22] "Answer questions at the speed of thought ith Tableau Desktop," Tableau Desktop, 2017. [Online]. Available: https://www.tableau.com/products/desktop.

[23] "Embedded Analytics and Reporting Software," Jaspersoft, 2017. [Online]. Available: https://www.jaspersoft.com/. 